\title{
High-density mobile LiDAR for measuring urban streetscape features
}

\author{
Yaneev Golombek ${ }^{1} \cdot$ Wesley Marshall ${ }^{1}$
}

Accepted: 2 October 2021 / Published online: 8 November 2021

(c) The Author(s), under exclusive licence to Springer Nature Limited 2021

\begin{abstract}
This study investigates the feasibility of utilizing high-density mobile Light Detection and Ranging (LiDAR) to measure urban streetscape features. The results suggest that mobile LiDAR's density allows for much smaller voxels than in the previous research and the ability to measure small urban streetscape features in 3D. This includes street trees, light/lampposts, street furniture, traffic and commercial signage, building window proportions, awnings, and enclosed courtyard restaurants. Moreover, mobile LiDAR facilitated measuring and categorizing these streetscape features in walkable, downtown-like streetscape environments. The ability to compartmentalize such streetscapes into smaller cubic foot voxels to be quantitatively measured and categorized could supplement or replace conventional audit-based streetscape measurement. This study introduces new methods-based on voxel data analysis - to compile accurate descriptive statistics of streetscape features and how they can be represented in 3D.
\end{abstract}

Keywords LiDAR $\cdot$ Streetscapes $\cdot$ Roadside features $\cdot$ Metrics $\cdot$ Voxels

\section{Introduction}

Lane widths, shoulder widths, curbs, and paint markings are all measured and designed with precise dimensions. Much less attention is given to vertical and outer streetscape features such as trees, benches, signage, and building frontage, to name a few. At the same time, there is over a century of literature regarding how such features are important for urban outcomes such as livability, for instance with writings from Sitte, Cullen, Appleyard, Rapoport, and Arnold (Sitte 1889; Cullen 1971; Appleyard 1980; Rapoport 1990; Arnold 1993). More recent research shows how these features may also impact road safety (Naderi 2003; Dumbaugh 2006; Wolf and Bratton 2006), economics (Ewing and Dumbaugh 2009; Marshall et al. 2018) as well as public health outcomes (Brownson et al. 2009; Purciel et al. 2009). Yet, the research regarding the role that streetscape features have on such outcomes remains somewhat conflicted, both in terms

Yaneev Golombek

yaneev.golombek@ucdenver.edu

Wesley Marshall

wesley.marshall@ucdenver.edu

1 Department of Civil Engineering, University of Colorado Denver, 1200 Larimer Street, P.O. BOX 173364, Denver, CO 80217, USA of the strength of the associations as well as the direction in some cases. These conflicts may be due to inconsistencies in measuring streetscape features.

Over the past decade, however, measuring-technique research for streetscape features has started to shift from audit-based methods (Ewing et al. 2005; Brownson et al. 2009; Ewing and Clemente 2013) towards GIS/remotesensing methods (Purciel et al. 2009; Yin and Shiode 2014; Harvey et al. 2017; Yin et al. 2017). In order to further reduce subjectivity, the most recent research is now beginning to use LiDAR (Light Detection and Ranging). Research by Golombek and Marshall, for instance, explored the streetscape mapping and streetscape feature detection/ extraction capabilities of publicly available aerial LiDAR data. More specifically, this research tested data derived from the national United States Geological Survey (USGS) 3D elevation program, which included Quality Level (QL) 2 LiDAR data (Golombek and Marshall 2019) as well as the four times denser QL1 LiDAR data (Golombek and Marshall 2020). QL2 LiDAR has a point density of at least 2 points per square meter while QL1 LiDAR is at least 8 points per square meter. These studies designated entire streetscapes into 3D pixels known as 'voxel' grids. With the lower USGS QL2 standard, feature extraction was primarily limited to street trees and buildings, while the QL1 standard expanded 
feature extraction to traffic lights, traffic signage, utility poles, walls, fences, as well as some larger street furniture.

These studies showed how LiDAR could be a valuable technology for providing accurate data in urban analysis and transportation-related research. Still, even the QL1 LiDAR point density standard had significant limits to what it could detect. For example, an urban QL1 dataset may collect only a few points on a street sign, which is enough to know the sign exists, but it neglects the overall dimensions and appearance of the sign. Smaller landscape features such as benches, garbage cans, and bike racks, to name a few, were not able to be detected with a QL1 dataset. Figure 1 depicts a comparison between QL1 and mobile LiDAR data, highlighting how some features are too small to be detected with QL1 LiDAR collection standards. Moreover, aerial LiDAR at these QL standards can detect top of buildings but not features in a peripheral view from the ground level such as windows, awnings, and building signage. Such features have also been shown to be important with respect to walkability.
Mobile, ground-based LiDAR, is dozens of times denser than publicly available QL1 aerial LiDAR data and is collected from the vantage point of the street. Many tests and advances over the past fifteen years have developed mobile LiDAR scanning platforms into an acceptable and accurate survey-grade feature collection mechanism (Haala et al. 2008; Williams et al. 2013). It seems that mobile LiDAR has the potential to quantitatively map various features within streetscapes, but this has not yet been studied.

The overarching goal of this study is to understand the role that mobile LiDAR, specifically its highly precise, accurate, and dense point-cloud, can play in quantitatively mapping and measuring features in an urban environment. This paper evaluates sample datasets collected with mobile LiDAR along several segments in a walkable town centertype in Denver, Colorado, and proposes two methods to quantify streetscapes with 3D voxel grids/zones. First, we seek to present measuring tools utilizing technologically advanced mobile LiDAR. More specifically, we seek to

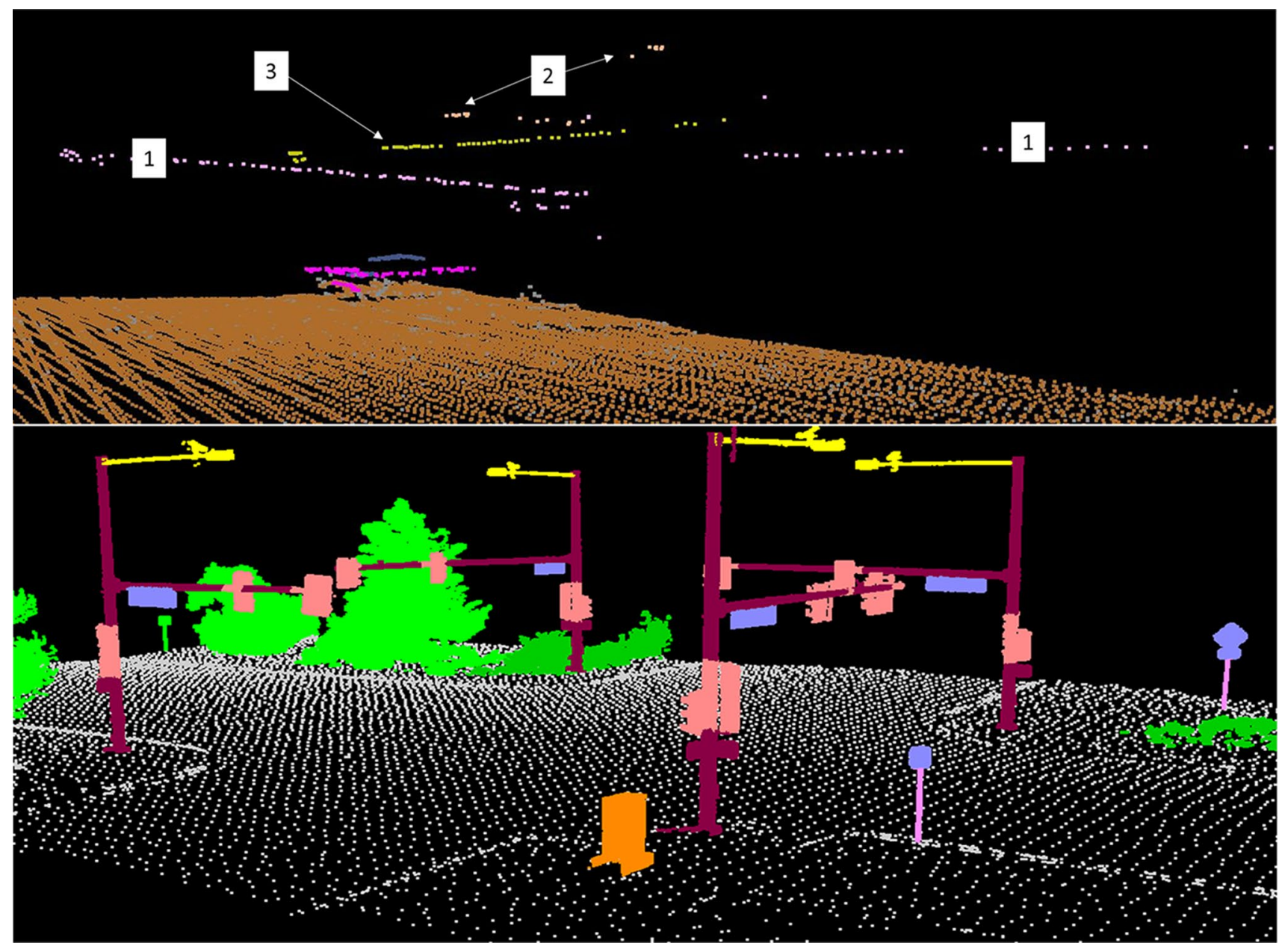

Fig. 1 Comparison of QL1 (top) data to Mobile LiDAR (bottom) data for two similar intersections (for the top image, $1=$ traffic light, $2=$ light posts above traffic light, $3=$ power lines) 
create volumetric descriptive statistics matrices for select streetscape features that have been cited as being affiliated with urban livability (perceptual qualities) and transportation-related outcomes (Ewing and Clemente 2013). Secondly, we create descriptive statistic matrices for critical urban streetscape features - such as street signage, traffic lights, and street furniture - that can be applied to urban and transportation research studies as well as inform municipal planning efforts.

This research has the potential to serve as an alternative or supplementary options to subjective human audit-based approaches for measuring streetscape features related to outcomes such as walkability and livability. The next section overviews the existing literature. This is followed by an indepth review of our data and methods. Lastly, we present our findings and highlight the implications of these efforts.

\section{Background}

Over the past few decades, many researchers have developed quantifiable measuring techniques for streetscapes. Ewing et al. were among the first, and with Clemente and Handy, they developed comprehensive audit-based techniques and published these techniques in various manuals (Ewing et al. 2005; Ewing and Clemente 2013). Their measuring techniques were audit based and dependent on the auditors having the appropriate skillset with respect to the ability to visually assess and measure seemingly subjective qualities (Brownson et al. 2009). In a related study, Ewing et al. measured twenty streetscape features over nearly 600 blocks in New York City related to pedestrian activity (Ewing et al. 2016). Again, many of the features being detected - such as street furniture, window measurements and proportions, building heights, various landscape features, and outdoors dining - tended to be measured via visual, subjective auditbased methods. Despite Ewing et al. checking for inter-rater reliability, these methods are time consuming and can still be subject to human error (Brownson et al. 2009). Brownson et al. (2009) evaluated twenty audit studies that evaluated built environments for health focused, physical activity reasons, which again primarily focused on crude visual assessments and not scientific, technology-based calculations.

Purciel et al. attempted to utilize basic GIS integration as an alternative to measuring some primary streetscape qualities. Purciel tested five of Ewing's primary perceptual qualities-imageability enclosure, human scale, transparency, and complexity - and found wide a wide range of correlation (0.28 to 0.89$)$ between GIS and the field-observed measures (Purciel et al. 2009). Yin and Shiode attempted to use remotely sensed images to digitize 2D features, followed by assessor GIS data in order to create 3D streetscape features, but they were limited to a few large features such as buildings and trees (Yin and Shiode 2014; Yin et al. 2017). These advancements are certainly important, though their accuracy is questionable when measuring the numerous small-scale streetscape features discussed by Ewing et al. over various studies.

Further advancing the use of spatial technologies with streetscape mapping, Harvey and Aultman-Hall addressed the streetscape measuring paradigm with respect to road safety outcomes while also incorporating aerial LiDAR (Harvey and Aultman-Hall 2015). They concluded that additional tree enclosure was significantly associated with a reduction in overall crashes. Harvey et al. also attempted to utilize spatial technologies to further address urban livability and concluded that GIS had limitations for collecting and/or addressing smaller features (Harvey et al. 2017).

Golombek and Marshall took potential urban streetscape measuring a step further and introduced voxel-based quantitative streetscape feature extraction of USGS QL1 and QL2 data, which creates descriptive statistics for how various features mentioned above are represented in a streetscape in 3D. These studies are among the most accurate methods to date, but as also mentioned in the introduction, many smaller streetscape features were still not detectable, even with the higher-density QL1 standard (Golombek and Marshall 2019, 2020). Also, ground-level vertical features such as windows, awnings, and building signage are important parts of streetscape studies but also not detectable with QL1 data.

Currently, research is limited on automated mobile LiDAR feature extraction methods, though most research on this topic occurred over the last few years and, fortunately, continues to advance. Lehtomaki et al. utilized segmentation, segment classification, and machine-learning classification to extract various street features from mobile LiDAR, including billboards, traffic poles, light posts, cars, and pedestrians (Lehtomäki et al. 2016). An issue with these methods is that the accuracy of feature classes ranged from 66.7 to $94.3 \%$, and the methods were only tested on $900 \mathrm{~m}$ of roadway, which is not enough for it to be considered a viably tested method. Some researches such as El-Halawany and Lichti (El-Halawany et al. (2011), Zheng et al. (2017), and Wu et al. (2017) have solely focused on automated streetpole extraction from mobile LiDAR. Their different methods of segmentation and clustering have led in some cases to a success rate of over $90 \%$ as well as a low false classification rate. Their results are encouraging with respect to the viability of automated methods.

Rivero et al. devised a method focused on the intensity value of traffic signs and utilized segmentation and clustering methods to automatically extract signs (Riveiro et al. 2016). Results successfully extracted around $80 \%$ of signs, though the authors appeared a little vague on the false-positive rate. Similar methods with some imagery and point cloud processing enhancements were used by Soilán et al. 
(2016), which yielded slightly better results than Rivero et al.. The false-positive rate, however, appeared high, and like other similar examples, the test area was too small to be considered a thoroughly tested solution. Perhaps the most successful street sign extraction methods came from Gargoum et al. who reported a near $100 \%$ success rate over three sample areas (Gargoum et al. 2018). These areas differed significantly from our sample study areas, as they were primarily in rural parts of Alberta, Canada, in areas where the signs appeared to be isolated from other nearby features. We further discuss if and how these methods apply to our study in the methods section below.

For transportation-related research, it is important to decipher between LiDAR technology and platforms used for discrete feature collection and navigational purposes. At present, much research is being done with navigational LiDAR to support autonomous vehicle navigation advancements. This form of LiDAR differs from discrete urban collection in that it focuses on quick, real-time identification of features mainly pertaining to the roadway itself such as curbs, centerlines, other vehicles, and pedestrians (Gao et al. 2018; Wang et al. 2019). Discrete collection LiDAR platforms, on the other hand, focus on collecting and storing data/features for analysis of all areas within a streetscape or urban environment.

Highly accurate LiDAR-based methods have made inroads for providing data support for measuring streetscape features. Yet, recent aerial-based LiDAR-based research (Golombek and Marshall 2020) still has limitations, especially for thoroughly collecting smaller features such as signs and street furniture. Other limitations include the ability to measure ground-based vertical assets that some streetscape research considers such as building windows. Mobile LiDAR has potential to fill these gaps. In addition to our previous studies (Golombek and Marshall 2019, 2020), examples above from Lehtomaki et al., Wu et al., Gargoum et al., and Yang et al. all utilized voxel-based approaches to advance their stated methods for measuring and quantifying urban features. Automated classification methods are quickly evolving for large-scale/ area classification but are currently questionable regarding their exactness. At present, manual classification of LiDAR data is viable and necessary for advancing urban street feature measuring and quantification. Though manual classification requires human evaluation, like Ewing et al.'s audit-based methods, the LiDAR science community accepts manual classification of urban features as inherently accurate. The automated LiDAR research noted here and elsewhere use manually classified LiDAR datasets as control to test the validity of automated LiDAR algorithms and results. Also, it is important to note that human, audit-based methods may never be automated. Therefore, LiDAR classification of urban street features, even if done manually for the time being, is still potentially a significant advancement from the subjective methods of the past noted above.

Another possible limitation has to do with occulated data. Occluded data relate to LiDAR data not reaching all aspects of features, which we address here because occluded data can prevent features from being fully captured and therefore improperly measured. Regarding the features themselves in their unobstructed environments, some urban mobile LiDAR studies addressed occluded objects. Studies by Wu et al. (2017) and Zheng et al. (2017) constructed automated methods for extracting light poles from mobile data, addressed the occlusion issue, and found that complete objects were captured well over $90 \%$ of the time. Yang et al. (2015) utilized methods to extract multiple features and also concluded that complete features were almost always captured despite potential occlusions. Lin et al. validated mobile LiDAR for completed tree understory collection (Lin et al. 2014). This research suggests that feature occlusion with mobile LiDAR may be limited.

This paper seeks to use mobile-based LiDAR to detect and collect urban streetscape features. The next section describes our data and methods.

\section{Data and methods}

\section{Overview}

This study investigates mobile LiDAR's dense groundlevel collection capabilities to assist the urban design/ analysis and transportation research community with two specific objectives.

The first objective is to provide descriptive statistic matrices that may be used as alternatives to some of the audit-based methods for streetscape evaluation with more precise and accurate data. Since the research strand tends to revolve around the walkability aspects of urban streetscapes, we attempt to focus on the sidewalk areas of busy downtown-like contexts. For these streetscapes, we also evaluate mobile LiDAR's ability to collect vertical building-face data that aerial LiDAR misses such as window proportions, awnings, and commercial signs.

Our second objective is to determine mobile LiDAR's capability of fitting small streetscape such as street signs, traffic lights, and streetscape furniture with a precise, voxel matrix. Mobile LiDAR should be highly effective for this level of analysis because our voxel size can be refined more than the 5 - $\mathrm{ft}$ vertical intervals used in the previous research (Golombek and Marshall 2019, 2020). 


\section{Data/data collection}

A Trimble MX9 was used to collect data for this study. The MX9 contains a spherical imaging system and three oblique view cameras. The MX9 contains Riegl VUX-1HA dual laser scanners that measure at $1000 \mathrm{kHz}$ with the scanner mirror rotating at 250 revolutions per second and a field of view of $360^{\circ}$. A Real-Time-Kinematic (RTK) base station was set up for post-processing purposes on a nearby National Geodic Survey (NGS) monument set at a 1-s interval collection rate. To confirm system accuracy, 13 ground control points (GCP) were established throughout the survey area that were no more than a half-mile apart from each other. Riegl's collection platform uses an internal 'multiple-timearound' procedure, which eliminates range ambiguities and helps remove data noise.

A four-mile segment was surveyed along Montview Boulevard in Denver, Colorado, between Colorado Boulevard and Havana Street. An additional nearby mile of roadway through a mixed-use town center area along E. 29th Avenue in Denver was also collected. Each of these segments was traveled twice, once in each direction. Since many features of interest are concentrated on the sides of streets, doing so provides additional assurance for full collection of features.

POSPac ${ }^{\circledR}$ was used to process telemetry of the Global Navigation Satellite System (GNSS) system, and we used RTK base station data to compute a corrected location of the vehicle path. Trimble Business Center (TBC) software was used to register/adjust overlapping data from the multiple runs. TBC also computed point cloud colorization using the registered images that were collected in-sync with the scans.

The combined runs were exported into LAS 1.4 format and $100-\mathrm{ft}$ by $100-\mathrm{ft}$ tiles. A control report was run against the GCPs that returned a root mean square error (RMSE) of $0.06-\mathrm{ft} / 1.83-\mathrm{cm}$ RMSE horizontal and a $0.122-\mathrm{ft} / 3.72-\mathrm{cm}$ RMSE vertical. Point cloud density consistently averaged over 2000 points per square meter. Target range was well over $100 \mathrm{~m}$, which was well above the tallest feature in the streetscapes.

We also obtained parcel data from the City and County of Denver to determine the right-of-way (ROW) for the Montview segment, as discussed below.

\section{Methods}

\section{Creating streetscape sample areas}

Similar to previous studies on quantitative streetscape measuring (Golombek and Marshall 2019, 2020), we seek to develop quantitative statistics of streetscape features. This first required defining streetscape corridor segments. Recent streetscape mapping studies used a method to divide the pre-determined segments into Thiessen proximal polygons (Golombek and Marshall 2019, 2020). To create a Thiessen polygon layer, only a point feature class is required, and the output Thiessen polygon dataset is configured where each individual non-overlapping polygon is closest to its associated input point. In the Montview dataset, we attempted to avoid segment cutoff at intersections since urban intersections tend to be focal areas with high activity and many traffic-related features we prefer to keep together. By establishing the input point feature class with these intersection centroids, the segment breaks occur at a subtle location somewhere between these intersections. Figure 2 depicts the Thiessen-based streetscape segments we created for Montview Boulevard using the ESRI ArcGIS ${ }^{\circledR}$ Thiessen polygonprocessing tool. The town-center streetscape polygons were created manually since the area of interest contained only a few small blocks.

Additionally for the Montview section, we designed the streetscape sample areas to include the full street right-ofway (ROW) that extend beyond the street curb. Extending the streetscape to include these peripheral views is important since the majority of objects in urban roadways that fall within a road user's peripheral view are located off the street itself. Therefore, we utilized Denver's parcel data around the area of interest (AOI), merged the parcel data together, and used an ESRI ArcGIS ${ }^{\circledR}$ erase function that erased all non-streetscape ROW areas from our AOI. For the Montview section, we created six streetscape polygon segments utilizing this method.

For the town center area, our approach was a little different. Since the focus is more on streetscape features related to walkability, we simply digitized the areas between the curb and the building, enclosed with a crosswalk on each side. We identified six sample streetscape areas, as shown on Fig. 2, that we assess in this study.

\section{Creating streetscape voxels for positional feature analysis}

A key objective of this study is to incorporate voxels to quantity streetscape features and compile descriptive statistics. Breaking up a streetscape into voxels creates userspecified height zones. A voxel is a pixel with a height or third-dimension component that can be useful for analyzing LiDAR data. Similar voxel methods are utilized in our previous street-feature voxel analysis studies (Golombek and Marshall 2019, 2020). In those papers, we determined thatgiven aerial LiDAR point densities - a 3-ft by 3 -ft horizontal and a 5 -ft vertical setting was optimal and appropriate.

The accuracy and density of mobile LiDAR data, however, allows more flexibility in setting voxel parameters. Lehtomaki et al. used a fix voxel size of $20 \mathrm{~cm}^{3}$ for their street feature study. Yang et al. used a super-voxel approach where the voxel size was more focused on the feature itself, 


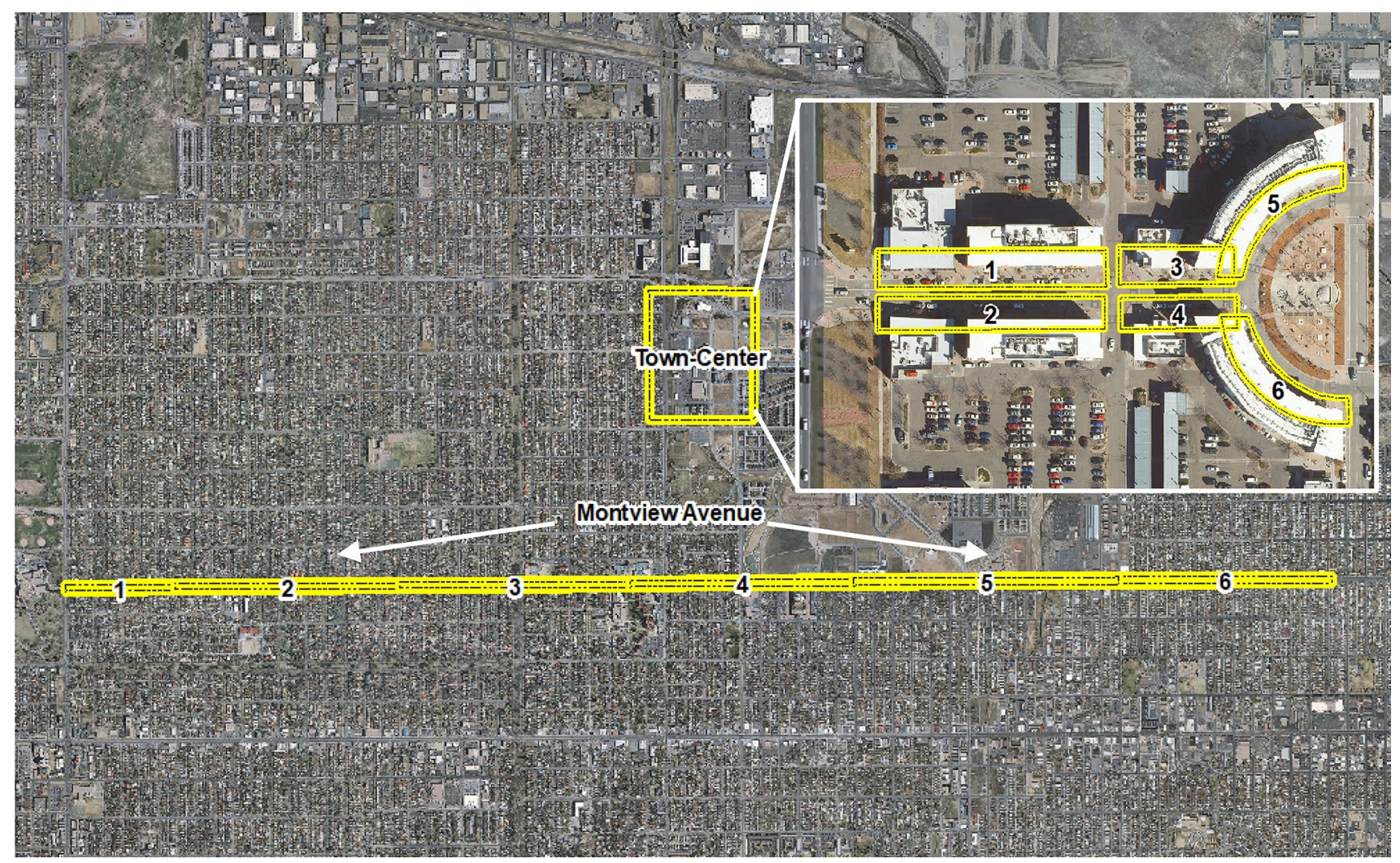

Fig. 2 Sample streetscapes for both Montview Boulevard and the town center area to the north

though their voxel size always seemed greater than $0.5 \mathrm{~m}^{3}$. With over a thousand points per meter collected and utilizing US feet as the linear unit, we suggest setting each voxel to a single cubic foot, or 1 -ft by 1 -ft by $1-\mathrm{ft}(x, y, z)$ dimension. We suggest this parameter because this dimension facilitates a simple calculating dimension and solid measuring basis for descriptive statistic metrics needed in the town center area. Ewing and Clemente often reference measuring features from ground to certain levels, like eye-level visibility (Ewing and Clemente 2013). If a streetscape was, for example, 500-ft long from crosswalk to crosswalk, $50-\mathrm{ft}$ wide from storefront/building to curb, and $15-\mathrm{ft}$ tall from ground to the above awnings, that streetscape quantitatively would total 375,000 cubic $\mathrm{ft}$. If we calculate that 10 landscape trees fill 7500 single cubic-foot voxels, then we can estimate that trees comprise 2 percent of that streetscape.

\section{LiDAR feature extraction methodology/classifying the data}

For the four-mile Montview segment, the goal is to devise comprehensive descriptive statistics of streetscape features that can be applied to various urban transportation research studies. Other than for street sign extraction, the existing literature did not provide viable automated approaches. Even the street sign extraction methods yielded results well below
$100 \%$ (with a high degree of false positives and false negatives) and have not been thoroughly tested at a macro scale. Gargoum et al. developed highly accurate automated street sign extraction results (Gargoum et al. 2018), though testing was primarily in rural areas where signs are isolated. Even if we utilize published automated methods, we would still have to manually assess the entire streetscape to check for false positives and false negatives. We also note, after previewing the Montview section, that many street signs are on the same horizontal poles as traffic lights, and some are small and/or obscured. For example in Fig. 3, a 'No Parking' sign may be on a light pole or power pole, but if it is not wider than the pole, the current automated methods would likely miss these signs. Additionally, the streetscape furniture and traffic lights require manual classification since we did not find adequate methods to automate extracting those features. An accuracy assessment on manually classified data is not necessary since many automated LiDAR classification experiments, including ones listed above, utilize manual classification for their control to assess accuracy. The accuracy specifications of the data are mentioned with the data collection platform specifications above.

Since our four-mile sample area is not overwhelmingly large, we utilized a manual classification approach with some automated LiDAR functions. The data's control 

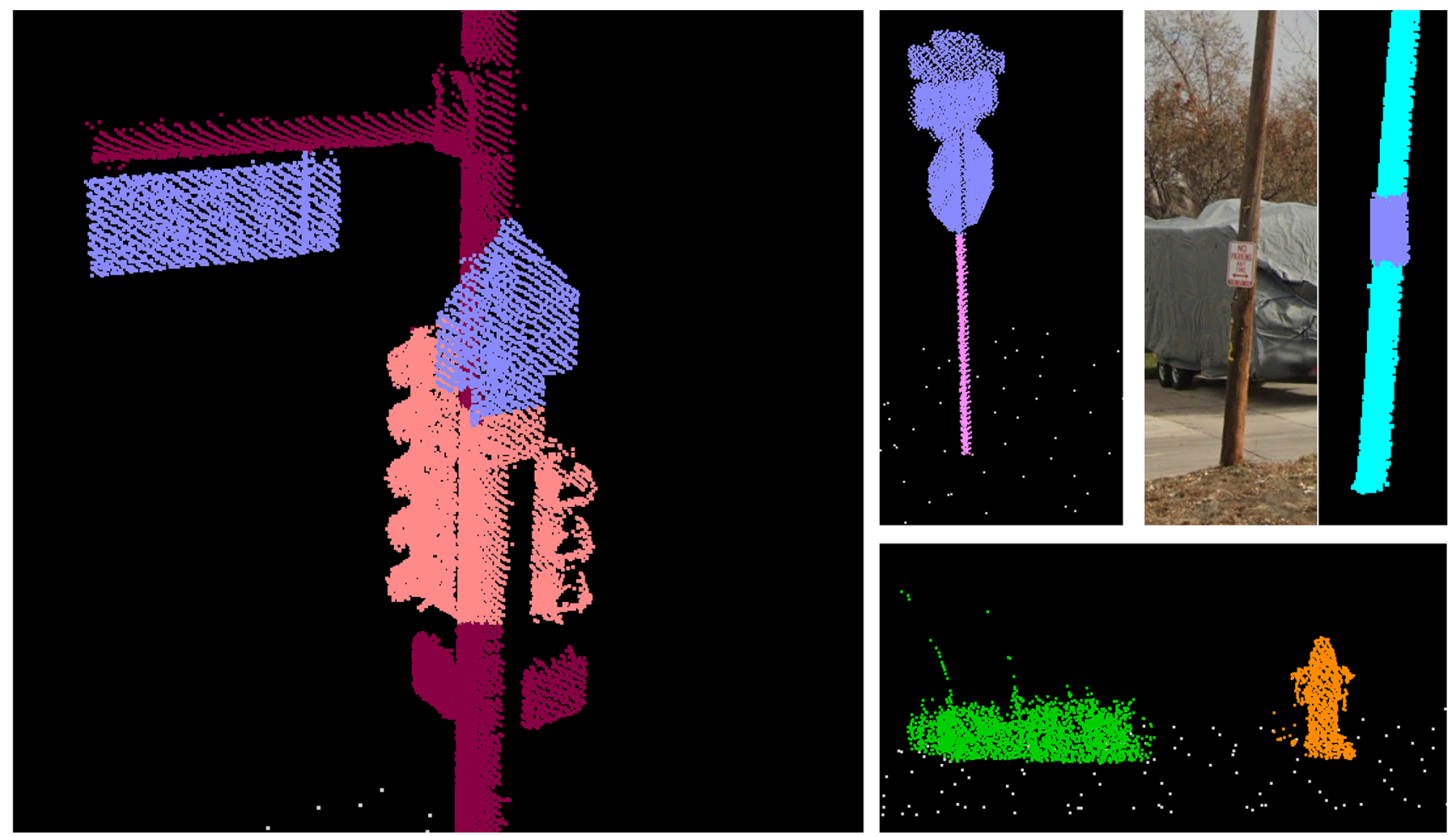

Fig. 3 Sample Features from Montview Boulevard (Left-Example of multiple features (signs, traffic signal, pole) grouped together; Top Center-Sign on pole; Top Right—No Parking sign on Pole; Bottom Right—Hydrant and low landscape vegetation)

reports, noted above, confirmed very high vertical and horizontal point-cloud accuracy. Also, automated LiDAR methods are often tested against manual classification for control, and we saw the same with automated urban mobile LiDAR feature extraction (Yang et al. 2015). We auto-filtered the data for ground points and also used an automated process to classify the remaining above-ground features together on a single LiDAR classification layer. We utilized Merrick \& Company's MARS ${ }^{\circledR}$ LiDAR processing software, which has a Google Earth simultaneous location feature, to follow the streetscape point-cloud in MARS ${ }^{\circledR}$. Paired with Google Earth on a separate screen, this allowed us to visually identify all street signs, traffic signals, and street furniture features (Fig. 4).

Once completed, we utilized a voxel application tool in MARS ${ }^{\circledR}$ that incorporates ground level and builds a user-specified voxel grid set to $1-\mathrm{ft}$ by $1-\mathrm{ft}$ by $1-\mathrm{ft}(x, y$, $z$ ) dimensions. This tool then applies the selected classified street furniture and street sign features into the voxel grids and exports a .dat Envi raster dataset, with each band within the dat file representing a unique user-specified voxel height zone. Each grid cell that is populated also has a count value that specifies how many LiDAR points fell into that 3D voxel grid cell. For this study, we are not very concerned with the amount of data in each grid cell, but rather the simple fact that classified LAS points are inside that grid cell. Table 1 presents a sample descriptive statistics output.

For the town center area, our descriptive statistic zones for the walkable streets are different because we focus more on the walkable areas between the curb and the buildings. For this, we use a different approach because we are interested in collecting and measuring features affiliated with the buildings themselves such as the windows, awnings, and hanging signs. Our approach for collecting these objects differs because flat objects against buildings, such as windows, cannot be extracted like typical streetscape objects. Also, LiDAR often gets obstructed at windows and does not yield returns.

We extracted windows and awnings with mobile LiDAR with the help of a web-based solution by Orbit GT technologies. The Trimble MX9 platform collected panoramic images in conjunction with the LiDAR. Since the frames of the windows are well defined based on the void of LiDAR points within the frames, the Orbit LiDAR software has an interface that allows 3D feature tracing of the LiDAR data. For windows and awnings, we essentially created vertical polygons. After the windows and awnings were drawn in the 3D Orbit software interface, it exported the polygons into a Google KML file, which were then converted into a 3D shapefiles. Since the features are in 3D, calculating the area of these polygons must be captured in 3D as well. 


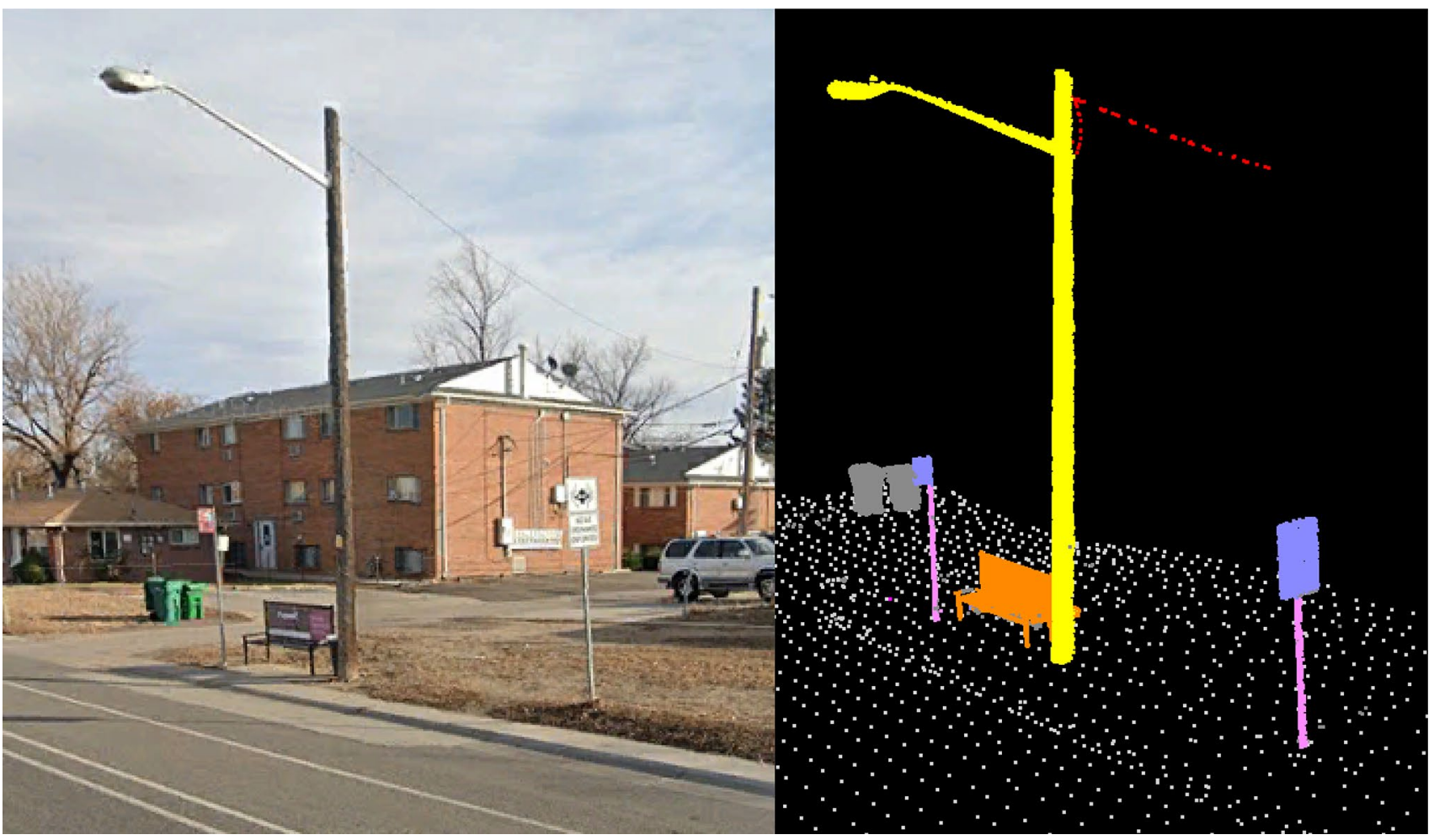

Fig. 4 Matching spaces in Google StreetView and Mobile LiDAR dataset

Table 1 Descriptive statistics of streetscape features from high-density mobile LiDAR derived from voxel intervals for the town center district for compiling streetscape statistics

\begin{tabular}{|c|c|c|c|c|c|c|c|c|c|c|c|c|c|}
\hline \multirow{2}{*}{$\begin{array}{l}\text { Area ID } \\
1\end{array}$} & \multirow{2}{*}{$\begin{array}{l}\text { Trees volume } \\
6124\end{array}$} & \multicolumn{2}{|c|}{ Trees points } & \multicolumn{2}{|c|}{ Street sign area } & \multicolumn{3}{|c|}{$\begin{array}{l}\text { Street } \\
\text { sign } \\
\text { points }\end{array}$} & \multirow{2}{*}{$\begin{array}{l}\begin{array}{l}\text { Light/ } \\
\text { lamp } \\
\text { point }\end{array} \\
9\end{array}$} & \multirow{2}{*}{$\begin{array}{l}\begin{array}{l}\text { Hanging } \\
\text { sign area }\end{array} \\
138\end{array}$} & \multirow{2}{*}{$\begin{array}{l}\text { Hang- } \\
\text { ing sign } \\
\text { count }\end{array}$} & $\begin{array}{l}\text { Street } \\
\text { furniture } \\
\text { area }\end{array}$ & \multirow{2}{*}{$\begin{array}{l}\begin{array}{l}\text { Street } \\
\text { furniture } \\
\text { count }\end{array} \\
19\end{array}$} \\
\hline & & 10 & & 126 & & 5 & 252 & & & & & 412 & \\
\hline 2 & 7280 & 10 & & 95 & & 4 & 386 & & 10 & 141 & 5 & 882 & 21 \\
\hline 3 & 3022 & 3 & & 121 & & 5 & 91 & & 5 & 89 & 3 & 339 & 12 \\
\hline 4 & 2347 & 4 & & 79 & & 3 & 109 & & 5 & 52 & 2 & 106 & 6 \\
\hline 5 & 2847 & 6 & & 60 & & 3 & 276 & & 6 & 94 & 3 & 135 & 4 \\
\hline 6 & 7502 & 6 & & 113 & & 4 & 268 & & 6 & 63 & 3 & 138 & 6 \\
\hline Area ID & Streetscape a & rea & Buildir & g length & $\begin{array}{l}\text { Builc } \\
\text { face }\end{array}$ & $\begin{array}{l}\text { ling } \\
\text { area* }\end{array}$ & $\begin{array}{l}\text { Window } \\
\text { count* }\end{array}$ & Window & $v$ area* & $\begin{array}{l}\text { Window } \\
\text { percentage* }\end{array}$ & Awnin & area* & $\begin{array}{l}\text { Enclosed open } \\
\text { restaurant area }\end{array}$ \\
\hline 1 & 3652 & & 281 & & 3091 & & 44 & 1373 & & $44.4 \%$ & 579 & & 1007 \\
\hline 2 & 3990 & & 282 & & 3102 & & 47 & 1527 & & $49.2 \%$ & 473 & & 636 \\
\hline 3 & 2861 & & 119 & & 1309 & & 20 & 343 & & $26.2 \%$ & 31 & & 56 \\
\hline 4 & 2926 & & 118 & & 1298 & & 28 & 455 & & $35.1 \%$ & 56 & & 165 \\
\hline 5 & 6175 & & 207 & & 2278 & & 58 & 1239 & & $54.4 \%$ & 1382 & & 0 \\
\hline 6 & 6488 & & 207 & & 2277 & & 61 & 1385 & & $60.8 \%$ & 1361 & & 120 \\
\hline
\end{tabular}

All area and volume units in Table 1 are in square feet and cubic feet

*Statistics are based on the ground-level views, up to the top of the first story or awning 
For this, we created an automated model in ESRI's $₫$ Model Builder to iterate through each polygon feature and created a temporary Triangulated Irregular Network (TIN) for each window or awning polygon. We then ran surface information statistics on each polygon, utilizing the TIN as the surface, which enables the area of each polygon to be calculated. This process created area statistics for features like windows that can detected with LiDAR but not directly extracted and classified. As mentioned above, urban design researchers such as Ewing et al. take into account quantity of features at eye level for perceptual qualities. Utilizing data in the LiDAR viewer allows an analyst to calculate 2D face area of a building (from ground to the awning), and after the TIN process for windows is complete, area and proportion of windows were calculated.

These streets have a handful of fenced outdoor restaurants, which are also focal features for studying urban streetscapes. We used the LiDAR data to locate fenced areas and drew 2D polygons around these areas to estimate the square footage. Akin to the Montview sample, we processed the remaining streetscapes features in the town centerincluding small landscape trees, light/lampposts, traffic signs, commercial signs (usually hanging in front of shops), and street furniture-via a single cubic-foot voxel grid. The result was then exported using dat Envi raster dataset with each zone as its own raster band.

It is also important to address the topic of occluded data and shadowing. Since mobile LiDAR emits horizontally, we need to address if features are prone to being obstructed by other features such as moving vehicles, parked vehicles, road users, or other objects. Fortunately, this collection occurred in early May 2020 when a Denver mandated stay-at-home order due to the COVID-19 pandemic was in effect, which significantly reduced traffic. Some parts of Montview Boulevard do not allow street parking, while the areas that do were mostly clear of parked cars. The mobile LiDAR vehicle operator was sure to always keep a safe distance from the few vehicles on the road. The town center's shops were either closed, or the few open restaurants were take-out only. A few street-side parked cars were present, though they did not obstruct or shadow features to a high extent. The literature reviews suggested that features collected by mobile LiDAR are rarely occluded, and despite horizontal collection angles, features usually tend to be completely collected due to mobile LiDAR's extreme point densities.

Additionally, it is important to address multiple features that may exist within a single voxel. This is most likely to occur when vegetation interferes with a manmade feature, such as a tree branch hanging over a sign or furniture object. In such cases, the sign is completely collected since the energy of the LiDAR pulse would deflect past the vegetation to the solid object and register as a multi-point pulse. If the pulse is deflected too far in another direction, the streetscape feature is still most likely to be completely collected given the over 2000 points per meter density described above. The occlusion discussion in the literature review highlights how feature occlusion with a mobile LiDAR platform of this nature is rare. Since streetscape features are processed independently of each other, a voxel can be counted more than once. The one limiting factor is that if the vegetation is in the same voxel as a manmade feature, but behind the feature, then the vegetation may be occluded. Given the relative size of landscape vegetation, we expect an immaterial amount of data to be occluded due to this scenario.

For the Montview and non-ground-level town center examples (see Table 1), we ran automated batch exports to convert the voxel height bands within each streetscape features's .dat raster into $1-\mathrm{ft}$ by 1 - $\mathrm{ft}$ vector polygons. We did this for each feature class we are analyzing. We then built an automated process through ESRI's® Model Builder to iterate through each individual (voxel height zone) vector polygon for each feature class. Model Builder was then programmed to perform a spatial join that sums all populated voxels for each feature in each voxel height zone and appends the data to each individual streetscape polygon, as noted in Fig. 2. The end result places all data into shapefile attribute tables that are cleaned up and exported into Excel tables. The Excel tables are the descriptive statistics that ultimately show how each streetscape is comprised of these features of interest. Tables 1 and 2 specifically break out the features discussed above into voxel height-based descriptive statistics, where each populated cell in these tables are cubic $\mathrm{ft}$ counts of that feature in those height zones.

Regarding street sign depth, the depth of most street signs are well below the 1 - $\mathrm{ft}$ linear depth of a voxel. Therefore, the street sign figure can be read as simple 2D area coverage in Tables 1 and 2. With 1-ft cubic voxels, the height, width, and depth of each voxel is $1 \mathrm{ft}$ each. Therefore, the sign statistics in Tables 1 and 2 can also be interpreted as 2D area coverage for each height zone since the length times the width (calculation of area) will always be multiplied times ' 1 .' In rare occurrences where very thin objects such as sign plates that are not completely vertical (which did not exist in our dataset), these voxel methods may limit our ability to accurately calculate those features. However, they can be calculated by manually measuring them in the data processing software, with the assistance of the high-resolution synchronous panoramic imagery.

\section{Results}

Table 1 shows sample results of the walkable streetscape areas. We specifically obtained volumetric streetscape data on trees, traffic signs, light/lampposts, hanging/commercial signs, street furniture, awnings, and enclosed open-air 
Table 2 Descriptive statistics of streetscape features from high-density mobile LiDAR derived from voxel intervals for Montview Boulevard

\begin{tabular}{|c|c|c|c|c|c|c|c|c|c|c|c|c|c|c|c|c|}
\hline Area ID & SS_1 & SS_2 & SS_3 & SS_4 & SS_5 & SS_6 & SS_7 & $\mathrm{TS}_{-}$ & $10 \mathrm{TS}$ & $11 \mathrm{~T}$ & $\mathrm{~S} \_12 \mathrm{~T}$ & S_13 T & TS_14 S & SF_1 & SF_2 & SF_3 \\
\hline 1 & 0 & 3 & 5 & 5 & 8 & 10 & 42 & 26 & 2 & & 25 & 24 & 17 & 63 & 54 & 46 \\
\hline 2 & 2 & 12 & 11 & 11 & 11 & 21 & 102 & 31 & 2 & & 27 & 22 & 37 & 215 & 191 & 109 \\
\hline 3 & 0 & 3 & 0 & 0 & 0 & 23 & 127 & 64 & 8 & & 87 & 01 & 57 & 332 & 334 & 256 \\
\hline 4 & 0 & 3 & 9 & 21 & 33 & 44 & 121 & 101 & 9 & & 96 & 93 & 58 & 254 & 266 & 269 \\
\hline 5 & 3 & 13 & 12 & 22 & 26 & 23 & 117 & 113 & 11 & & 09 & 12 & 77 & 803 & 661 & 468 \\
\hline 6 & 0 & 2 & 6 & 22 & 22 & 18 & 114 & 61 & 6 & & 58 & 53 & 20 & 305 & 445 & 301 \\
\hline Area ID & SS_9 & SS_10 & SS_11 & SS_12 & SS_13 & SS_14 & 4 SS_15 & SS_16 & TS_15 & TS_16 & TS_17 & TS_18 & TS_19 & SF_4 & SF_5 & SF_6 \\
\hline 1 & 116 & 102 & 102 & 95 & 52 & 16 & 18 & 16 & 0 & 0 & 0 & 16 & 34 & 31 & 25 & 23 \\
\hline 2 & 289 & 292 & 292 & 267 & 105 & 20 & 15 & 13 & 38 & 16 & 15 & 7 & 2 & 67 & 24 & 19 \\
\hline 3 & 308 & 298 & 283 & 231 & 110 & 68 & 51 & 56 & 37 & 50 & 44 & 28 & 16 & 191 & 129 & 134 \\
\hline 4 & 260 & 222 & 227 & 193 & 92 & 31 & 30 & 44 & 36 & 5 & 30 & 83 & 113 & 193 & 138 & 96 \\
\hline 5 & 287 & 265 & 206 & 137 & 38 & 12 & 6 & 22 & 41 & 24 & 23 & 89 & 170 & 394 & 354 & 267 \\
\hline 6 & 306 & 279 & 188 & 107 & 11 & 2 & 0 & 21 & 15 & 29 & 101 & 106 & 161 & 210 & 94 & 105 \\
\hline Area ID & SS_17 & SS_18 & SS_19 & SS_20 & SS_21 & 1 SS_22 & 2 SS_23 & SS_24 & TS_20 & TS_21 & TS_22 & TS_23 & 3 TS_24 & SF_7 & SF_8 & SF_9 \\
\hline 1 & 10 & 8 & 31 & 33 & 43 & 21 & 17 & 12 & 63 & 74 & 47 & 25 & 7 & 12 & 11 & 0 \\
\hline 2 & 14 & 13 & 2 & 0 & 0 & 0 & 0 & 0 & 0 & 0 & 0 & 0 & 0 & 9 & 4 & 4 \\
\hline 3 & 63 & 51 & 38 & 12 & 5 & 13 & 13 & 9 & 4 & 0 & 0 & 0 & 0 & 113 & 99 & 40 \\
\hline 4 & 20 & 18 & 91 & 89 & 69 & 5 & 5 & 0 & 165 & 128 & 69 & 18 & 4 & 103 & 13 & 4 \\
\hline 5 & 96 & 83 & 113 & 98 & 112 & 48 & 21 & 13 & 209 & 182 & 125 & 40 & 2 & 262 & 295 & 289 \\
\hline 6 & 56 & 86 & 77 & 48 & 21 & 18 & 0 & 0 & 102 & 64 & 3 & 0 & 0 & 79 & 94 & 67 \\
\hline Area ID & & & Squar & re footag & ge per tile & & Total in & d. signs & & & Total tr: & raffic ligh & ht units & & $\begin{array}{l}\text { Total st } \\
\text { furnitur } \\
\text { items }\end{array}$ & \\
\hline 1 & & & 250,8 & & & & 34 & & & & 9 & & & & 11 & \\
\hline 2 & & & 510,9 & & & & 75 & & & & 10 & & & & 32 & \\
\hline 3 & & & 521,1 & & & & 91 & & & & 17 & & & & 37 & \\
\hline 4 & & & 508,7 & & & & 95 & & & & 26 & & & & 42 & \\
\hline 5 & & & 601,7 & & & & 107 & & & & 35 & & & & 89 & \\
\hline 6 & & & 485,8 & & & & 101 & & & & 24 & & & & 38 & \\
\hline
\end{tabular}

All units are in cubic feet of coverage

Numeric figures after each abbreviation indicates voxel foot-height zone above ground

$S S$ street signs, $T S$ traffic signals, $S F$ street furniture

restaurants. We also obtained street level calculations of building coverage, window coverage, and window proportions related to their buildings. Figure 5 shows an example of window extraction. Figure 6 shows an example of walkable streetscape features classified.

Table 2 displays results of smaller urban features such as street signs, traffic lights, and street furniture. We display processing results for street signs, traffic lights, and street furniture in single-foot elevation layer voxel zones in an effort to provide descriptive statistic matrices. Figure 7 shows an example of single cubic-foot voxels covering a walkable streetscape.

For the town center area data presented in Table 1, we utilized six single-block segments shown in Fig. 2. We obtained these values by creating a similar descriptive statistic breakdown used in previous street-feature voxel categorizing studies (Golombek and Marshall 2019, 2020), which is similar to the Table 2 descriptive statistic structure. Since the results of Table 2 represent area/volume coverage at each voxel height zone, we added these figures together for each feature to determine total volumetric coverage, which is more in line with the sort of streetscape metrics (Purciel et al. 2009; Ewing and Handy 2009; Ewing et al. 2016) that we are trying to enhance. Whereas traditional methods may show crude tree counts and estimate their sizes or count windows and estimate their proportion, Table 1 shows that trees comprise between 2347 cubic $\mathrm{ft}$ and 7502 cubic $\mathrm{ft}$ of the 6 sample streetscapes. 


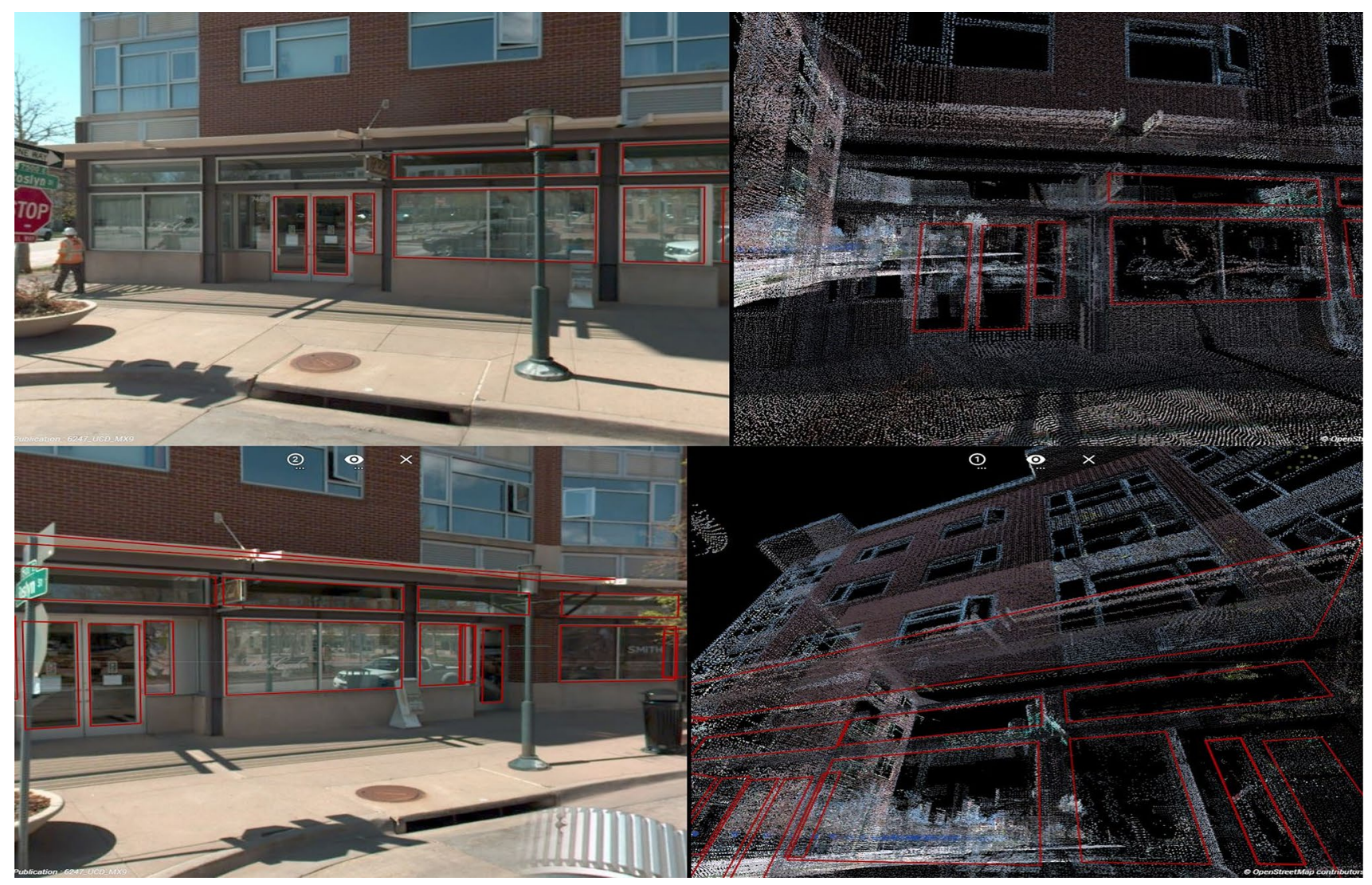

Fig. 5 Example of collecting windows off imagery and LiDAR point cloud (in the top photo, a snapshot, taken while classification was in progress, shows classified or collected windows on the right and not-yet classified windows on the left)

This statistic can impact the perceptual quality of human scale. Human scale refers to size of physical elements that match size and proportions of humans (Ewing and Clemente 2013). According to Arnold (1993), increased canopy are preferred among pedestrians since they mitigate intimidation caused by large surrounding buildings and wide streets and these LiDAR-based methods now allow for total physical coverage to be counted, as opposed to crude feature counts done previously. Increased coverage of street furniture and window coverage also affect human scale (Ewing and Clemente 2013). Regarding window coverage, Table 1 also shows that window coverage range from 26 to 61 percent for the sample streetscapes. This is important to note since previous audit-based evaluations called for human auditors to simply visually estimate proportions, which according to Brownson et al. (2009) is prone to human error.

As another example, areas 5 and 6 are very similar in size and shape and have the same number of trees. Auditbased evaluations simply count trees. Yet, area 6 has nearly three times the amount of actual tree coverage per Table 1 . Though this research does not assess reasons for these differences, some examples for this occurrence may include tree age. Another possibility is that the taller trees may be positioned to receive more sunlight. The LiDAR collection density, accuracy, project specs, and the project control report clearly depict that these discrepancies were not caused by errors or lack of capabilities from the mobile LiDAR collection effort. Mobile LiDAR's high energy and dense, emission of over 2000 points per meter limits occlusion and penetrates tree canopies. In fact, the existing mobile LiDAR studies relating to street features and tree collection show very limited (if any) occlusion from high-density mobile LiDAR (Yang et al. 2015; Lin et al. 2014; Wu et al. 2017; Zheng et al. 2017). Therefore, mobile LiDAR's results clearly show how volumetric calculations are more justifiable than simple crude counts of features.

Table 2 includes the results of our Montview Boulevard analysis. In Table 2, the numbers next to each abbreviation designate the lower part of the height zone, so height for example SS_1 (SS = Street Signs) would be from 1-ft above ground to 2-ft above ground. TS (TS $=$ Traffic Signal) starts at TS_10, where the first height zones where traffic signals are present are around $10 \mathrm{ft}$ above ground, since TS_10 is the voxel height zone from $10 \mathrm{ft}$ to $11 \mathrm{ft}$. Street Furniture (SF) starts at ground, though we eliminate the zero to $1-\mathrm{ft}$ zone because many features at this level may be confused 


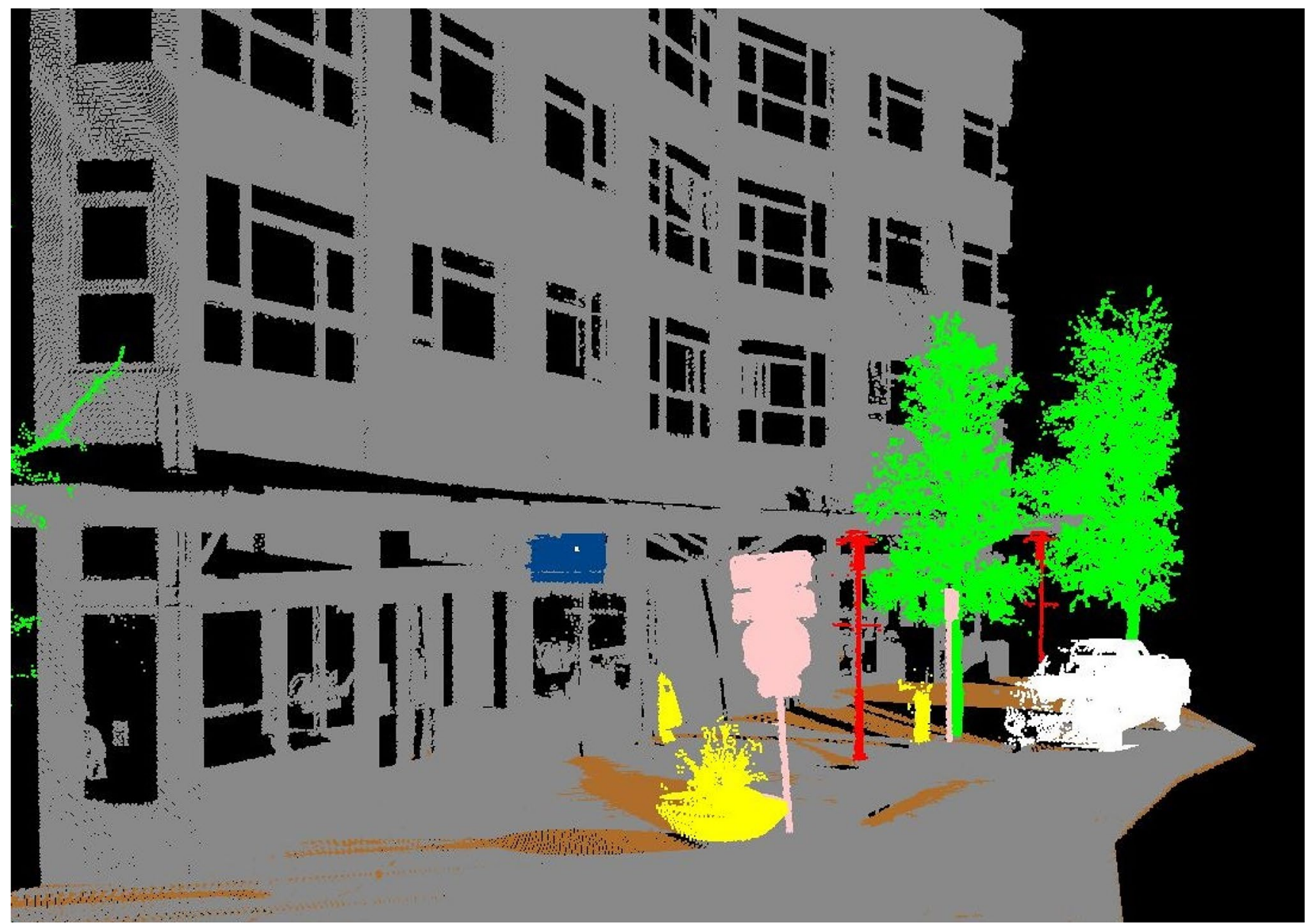

Fig. 6 Sample of feature classification in the Town Center streetscape (trees are green, traffic signage pink, lampposts red, street furniture yellow, commercial sign blue, parked car white)

with misclassified ground points. Street furniture included benches, garbage cans, bus stops, permanent non-traffic signs, permanent décor, and any miscellaneous features that would not fit into any other common streetscape feature class.

For the Table 2 Montview sample, we see where signs, signals, and street furniture are most prominent. For street signs, it appears that most activity is between 8 and $12 \mathrm{ft}$, since before $8 \mathrm{ft}$ and after $12 \mathrm{ft}$, these zones show much less activity. We also see more than a doubling of street sign face coverage between 7 and $8 \mathrm{ft}$, and this statistic more than halves after $12 \mathrm{ft}$. Traffic signals do not populate voxels until $10 \mathrm{ft}$ above ground. As the socioeconomics change, so do the traffic signals. Montview Boulevard begins in a highly tree-covered, wealthy neighborhood. The traffic signals appear lower because many of them are flashing signals on the street sides. Further east, Montview transitions from Denver to Aurora into a lower socioeconomic neighborhood. Here, we see more traffic signals, which appear to be higher above ground. Height above ground is important to consider as it relates to streetscape complexity. Rapoport
(1990) explains that complexity is related to noticeable differences to which a viewer is exposed per unit of time. Both pedestrians and motorists need features adequately placed in space to receive information at perceivable rates (Ewing and Clemente 2013). Additionally, past research shows how placement of these features among others affect urban transportation safety (Naderi 2003; Dumbaugh 2006; Wolf and Bratton 2006). Table 2 highlights additional examples of accurate street feature measurements that, if applied to discussed urban transportation outcome research, could reshape results.

\section{Conclusion}

Mobile LiDAR data have proven to be useful for measuring urban streetscape features, especially walkable streetscapes, and infrastructure components that enclose a streetscape. To our knowledge, our results provide the most accurate volumetric calculations of various features in the literature to date. Some examples include street signage, ranging from 


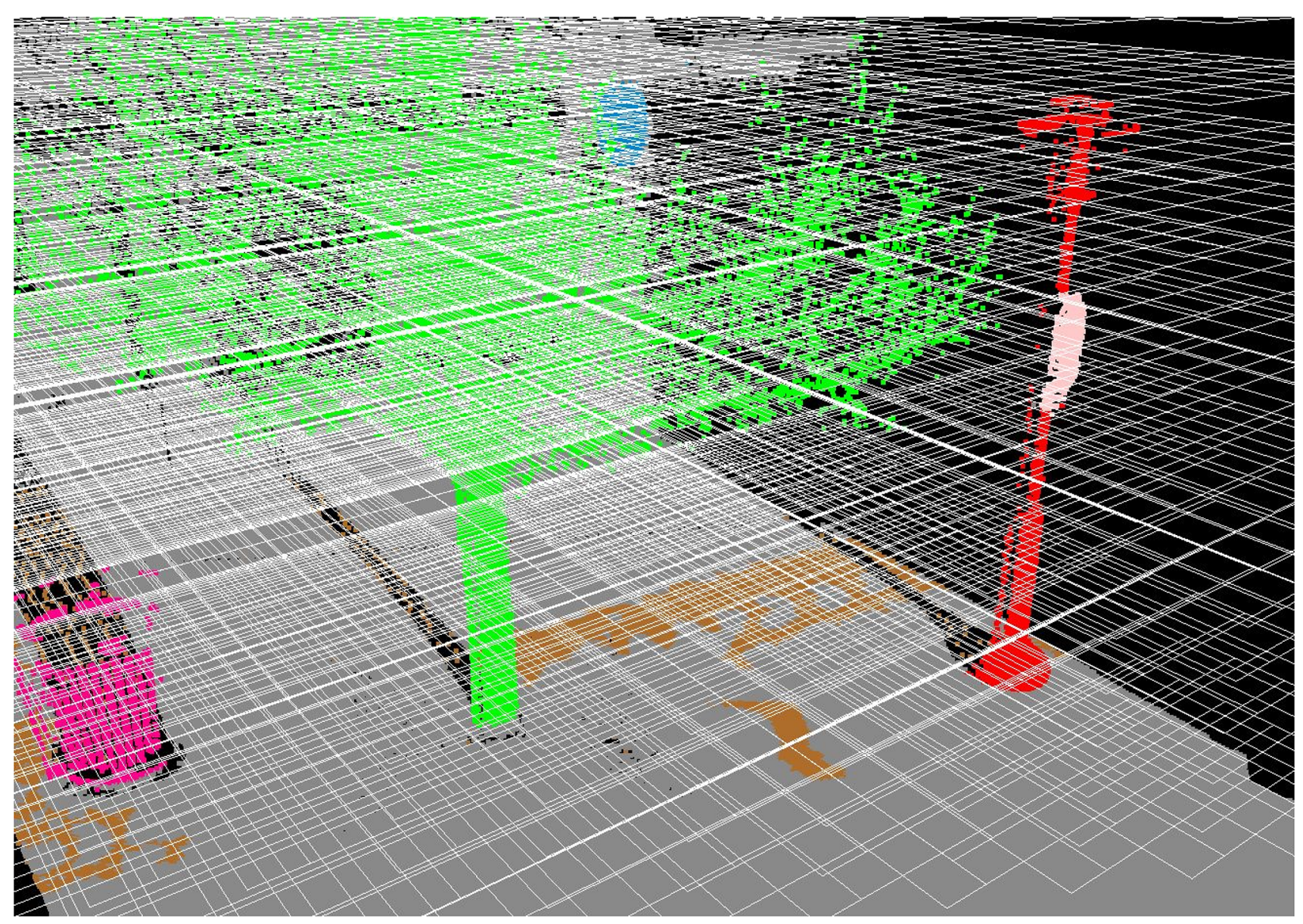

Fig. 7 Example of single cubic ft voxels covering walkable streetscape area

60 cubic $\mathrm{ft}$ to 126 cubic $\mathrm{ft}$, and hanging commercial signs, ranging from 52 cubic $\mathrm{ft}$ to 141 cubic $\mathrm{ft}$ of total coverage throughout individual streetscape segments. Our results also provide examples of actual window areas, and we see significant discrepancies between window area as a proportion or percentage of the building's street level face, ranging from $26 \%$ to over $60 \%$. Enclosed open-air restaurants range from zero to over 1000 square $\mathrm{ft}$. This level of descriptive statistics provides a unique niche for mobile LiDAR that cannot be obtained with publicly available aerial LiDAR.

For urban streets, our results also show that mobile LiDAR enables access to refined descriptive statistics of critical, smaller features such as street furniture, traffic signs, and traffic lights. The single cubic-foot voxel zones provided us with the ability to, for instance, identify that street signs appear most prevalent between 8 and $12 \mathrm{ft}$; we also see street furniture most prevalent at lower height zones and topping off around $10 \mathrm{ft}$.

We believe mobile LiDAR analytics has the potential to quantitatively supplement and/or replace time consuming, and likely subjective, audit-based streetscape measures. We also believe the methods discussed in this study allow for such quantitative assessments to be conducted far more efficiently than similar physical, in-person assessments. For instance, the town center area represents walkable streets that are similar to areas analyzed by Ewing et al. (2005). The audit-based measuring techniques utilized by Ewing, along with many of the audit-based measuring techniques evaluated by Brownson et al. (2009), are commonly dedicated to street walkability research. Whereas Cullin understood how urban features were important to desirability, making them feel like outdoor rooms (Cullen 1971), Ewing's group consolidated urban features into perceptual quality groups. Specifically, they considered factors such as enclosure, complexity, human scale, transparency, and imageability (Ewing and Clemente 2013) by visually assessing items. An example from Table 1 relating to perceptual qualities are street trees measures that could be used to calculate enclosure (Ewing and Clemente 2013). Street lamps/lights, street trees, and street furniture are factors of measuring human scale and complexity (Ewing and Clemente 2013). Window area and proportions are factors of measuring human scale and transparency (Ewing and Clemente 2013). Hanging signs 
and fenced courtyard restaurants are measures of imageability (Ewing and Clemente 2013). We can now far more objectively quantify these perceptual qualities with mobile LiDAR.

The Ewing et al. (2016) audit-based study mentioned above concludes that only three out of twenty streetscape features, many of which were evaluated above, have significant positive correlations with pedestrian counts. We argue throughout this study that audit-based methods are subjective while modern feature measuring/surveying technologies, such as LiDAR, have advanced to provide significantly more accurate feature measuring. The same can be said for many of the twenty audit-based studies that Brownson et al. (2009) surveyed. It is very possible that utilizing mobile LiDAR may lead to different conclusions than Ewing et al.'s example.

Moreover, this research can also contribute to urban traffic outcome studies, as various researchers remain conflicted regarding the roles that street trees and other streetscape features have on road safety outcomes. Marshall et al., for instance, recently completed a study suggesting that street trees are associated with better road safety outcomes, which runs counter to conventional wisdom (Marshall et al. 2018). Our results have potential to quantify streetscapes, which can supplement the audit-based efforts and help resolve longstanding inconsistencies over what features actually lead to better road safety outcomes.

It is important to point out some potential limitations for a larger scale study of this nature. Most importantly, this study utilized manual classification methods. If this study were performed on a larger scale, similar to the hundreds of blocks that cited researchers have performed their auditbased or GIS-based methods, it will be important to improve automated LiDAR classification methods. Per our discussion above, the automated methods appear to be improving, with significant advancements over the past few years. Still, some features still have no automated methods and may require manual classification. Regardless, any automated improvement will significantly reduce the amount of time it takes to properly classify data, even though large-scale, multi-feature manual classification is currently common practice and economically viable in some situations.

We believe our study presents a more comprehensive and accurate approach to quantifying an urban streetscape than can be found in the current literature. It is important to point out that we used a 1 cubic-ft voxel as our measuring unit, which may slightly overestimate the actual size of some features such as signs, poles, or branches that slightly protrude into the feature's outer-most voxel. Zheng et al. mention that these fixed sizes are usually efficient for measuring features, but the set voxel size can influence results. We chose to use the 1 cubic $\mathrm{ft}$ because of the simplicity involved in calculating statistics with a cubic unit of ' 1 .' It was also smaller than had been used in the previous research. Per the point-cloud density and accuracy standards listed above, voxel sizes can be adjusted to even smaller sizes for perhaps improved results.

Additionally, shadowing due to parked vehicles, or similar obstructions, would be a limitation. As mentioned, the COVID-19 pandemic heavily reduced parked vehicles. Though city coordination, or perhaps coordination with street-sweeping days, may be necessary to limit parked vehicles when collecting data.

This research shows mobile LiDAR to be a valuable tool for quantitatively mapping streetscape features in 3D. Our methods will hopefully provide transportation and urban design researchers valuable tools to help assess the roles that various streetscape features play in urban analysis and urban transportation outcomes.

Acknowledgments The work presented in this paper was conducted with support from the University of Colorado Denver and the Mountain Plains Consortium, a University Transportation Center funded by the U.S. Department of Transportation.

\section{References}

Appleyard, D. 1980. Livable Streets: Protected Neighborhoods? The Annals of the American Academy of Political and Social Science 451 (1): 106-117.

Arnold, H.F. 1993. Trees in Urban Design. New York: Van-Nostrand Reinhold.

Brownson, R.C., C.M. Hoehner, K. Day, A. Forsyth, and J.F. Sallis. 2009. Measuring the Built Environment for Physical Activity: State of the Science. American Journal of Preventive Medicine 36 (4): S99-S123.

Cullen, G. 1971. The Concise Townscape. New York: Van-Nostrand Reinhold.

Dumbaugh, E. 2006. Design of Safe Urban Roadsides: An Empirical Analysis. Transportation Research Record 1961: 74-82.

El-Halawany, S., A. Moussa, D.D. Lichti, and N. El-Sheimy. 2011. Detection of Road Curb from Mobile Terrestrial Laser Scanner Point Cloud. International Archives of the Photogrammetry, Remote Sensing and Spatial Information Science XXXVIII (August): 109-114.

Ewing, R., and E. Dumbaugh. 2009. The Built Environment and Traffic Safety A Review of Empirical Evidence. Journal of Planning Literature. 23 (4): 347-367.

Ewing, R., and O. Clemente. 2013. Measuring Urban Design. Washington, DC: Island Press.

Ewing, R., O. Clemente, S. Handy, R.C. Brownson, and E. Winson. 2005. Measuring Urban Design Qualities Related to Walking. Active Living Research Program. https://activelivingresearch. org/sites/activelivingresearch.org/files/FinalReport_071605.pdf.

Ewing, R., and S. Handy. 2009. Measuring the Unmeasurable: Urban Design Qualities Related to Walkability. Journal of Urban Design. 14 (1): 65-84.

Ewing, R., A. Hajrasouliha, K.M. Neckerman, M. Purciel-Hill, and W. Greene. 2016. Streetscape Features Related to Pedestrian Activity. Journal of Planning and Education Research. 36 (1): 5-15.

Gao, H., B. Cheng, K. Li, J. Zhao, and L. Deyi. 2018. Object Classification Using CNN-Based Fusion of Vision and LIDAR in 
Autonomous. IEEE Transactions of Industrial Informatics 14 (9): 4224-4231.

Gargoum, S., K. El-basyouny, J. Sabbagh, and K. Froese. 2018. Automated Highway Sign Extraction Using Lidar Data. Transportation Research Record. 2643 (1): 1-8.

Golombek, Y., and W.E. Marshall. 2019. Use of Aerial LiDAR in Measuring Streetscape and Street Trees. Transportation Research Record. 2673 (4): 125-135.

Golombek, Y., and W.E. Marshall. 2020. Measuring Streetscape Features with High Density Aerial LiDAR. Transportation Research Record 2674 (11): 192-206.

Haala, N., M. Peter, J. Kremer, and G. Hunter. 2008. Mobile Lidar Mapping For 3D Point Cloud Collection in Urban Areas-A Performance Test. Procedings XXIst International Society Photogrammetry and Remote Sensing Congress, 1119-1124.

Harvey, C., and L. Aultman-Hall. 2015. Urban Streetscape Design and Crash Severity. Transportation Research Record. 2500: 18.

Harvey, C., L. Aultman-Hall, A. Troy, and S.E. Hurley. 2017. Streetscape Skeleton Measurement and Classification. Environment and Planning B: Urban Analytics and City Science 44 (4): 668-692.

Lehtomäki, M., A. Jaakkola, J. Hyyppä, J. Lampinen, H. Kaartinen, and A. Kukko. 2016. Mobile Laser Scanning Point Clouds in a Road Environment. IEEE Transactions on Geoscience and Remote Sensing. 54 (2): 1226-1239.

Lin, Y., M. Holopainen, V. Kankare, and J. Hyyppä. 2014. Validation of Mobile Laser Scanning for Understory Tree Characterization in Urban Forest. IEEE Journal of Selected Topics in Applied Earth Observations and Remote Sensing. 7 (7): 3167-3173.

Marshall, W.E., N. Coppola, and Y. Golombek. 2018. Urban Clear Zones, Street Trees, and Road Safety. Research in Transportation Business and Management 29: 136-143.

Naderi, J.R. 2003. Landscape Design in the Clear Zone: The Effect of Landscape Variables on Pedestrian Health and Driver Safety. Transportation Research Record 1851: 119-130.

Purciel, M., K.M. Neckerman, G.S. Lovasi, J.W. Quinn, C. Weiss, M.D.M. Bader, R. Ewing, and A. Rundle. 2009. Creating and Validating GIS Measures of Urban Design for Health Research. Journal of Environmental Psychology 29 (4): 457-466.

Rapoport, A. 1990. History and Precedent in Environmental Design, 540. Dordrecht: Springer.

Riveiro, B., L. Díaz-vilariño, B. Conde-Carnero, M. Soilán, and P. Arias. 2016. Automatic Segmentation and Shape-Based
Classification of Retro-Reflective Traffic Signs from Mobile LiDAR Data. IEEE Journal of Selected Topics in Applied Earth Observations and Remote Sensing. 9 (1): 295-303.

Sitte, C. 1889. City Planning According to Artistic Principles.

Soilán, M., B. Riveiro, J. Martínez-sánchez, and P. Arias. 2016. Traffic Sign Detection in MLS Acquired Point Clouds for Geometric and Image-Based Semantic Inventory. ISPRS Journal of Photogrammetry and Remote Sensing. 114: 92-101.

Wang, H., X. Lou, Y. Cai, Y. Li, and L. Chen. 2019. Real-Time Vehicle Detection Algorithm Based on Vision and Lidar Point Cloud Fusion. Journal of Sensors. https://doi.org/10.1155/2019/84739 80.

Williams, K., M.J. Olsen, G.V. Roe, and C. Glennie. 2013. Synthesis of Transportation Applications of Mobile LIDAR. Remote Sensing. 5 (9): 4652-4692.

Wolf, K.L., and N. Bratton. 2006. Urban Trees and Traffic Safety: Considering U.S. Roadside Policy and Crash Data. Arboriculture and Urban Forestry 32 (4): 170-179.

Wu, F., C. Wen, Y. Guo, J. Wang, Y. Yu, and C. Wang. 2017. Rapid Localization and Extraction of Street Light Poles in Mobile LiDAR Point Clouds: A Supervoxel-Based Approach. IEEE Transactions Intelligent Transportation Systems 18 (2): 292-305.

Yang, B., Z. Dong, G. Zhao, and W. Dai. 2015. Hierarchical Extraction of Urban Objects from Mobile Laser Scanning Data. ISPRS Journal of Photogrammetry and Remote Sensing 99: 45-57.

Yin, L. 2017. Street Level Urban Design Qualities for Walkability: Combining 2D and 3D GIS Measures. Computers, Environment and Urban Systems 64: 288-296.

Yin, L., and N. Shiode. 2014. 3D Spatial-Temporal GIS Modeling of Urban Environments to Support Design and Planning Processes. Journal of Urbanism: International Research on Placemaking and Urban Sustainability 7 (2): 152-169.

Zheng, H., R. Wang, and S. Xu. 2017. Recognizing Street Lighting Poles from Mobile LiDAR Data. IEEE Transactions on Geoscience Remote Sensing 55 (1): 407-420.

Publisher's Note Springer Nature remains neutral with regard to jurisdictional claims in published maps and institutional affiliations. 